\title{
Migration and proliferation of retinal pigment epithelium on extracellular matrix ligands
}

Hao Wang, MS, MD; Yancy Van Patten, MS; Ilene K. Sugino, MA; Marco A. Zarbin, MD, PhD*

Institute of Opthalmology and Visual Science, University of Medicine and Dentistry of New Jersey, New Jersey Medical School, Newark, NJ

\begin{abstract}
We compared aged adult and fetal retinal pigment epithelium (RPE) migration and proliferation in cell culture. Aged adult RPE resurfaced on dishes coated with human or mouse laminin, human or rat collagen I, human or mouse collagen IV, or human fibronectin. Resurfacing was best on bovine corneal endothelial cell extracellular matrix. Resurfacing was worst on mouse laminin. Fetal RPE resurfacing was robust on all surfaces studied except human and mouse laminin. In general, fetal RPE resurfacing was much greater than that seen with aged RPE on comparable surfaces. The degree of cell proliferation (labeled by Ki-67) was much greater in fetal than adult RPE cells.
\end{abstract}

Key words: age-related macular degeneration, aged retinal pigment epithelium, bovine corneal endothelial cell extracellular matrix, cell migration, cell proliferation, choroidal neovascularization, extracellular matrix, fetal retinal pigment epithelium, retinal pigment epithelium resurfacing, wound healing.

\section{INTRODUCTION}

Age-related macular degeneration (AMD) is a major cause of irreversible loss of central vision among persons over the age of 55 and among U.S. veterans [1-5]. Approximately 70 percent of cases of severe visual loss in AMD are due to growth of abnormal blood vessels from the choriocapillaris into the subretinal space. This abnormal vessel growth is caused by choroidal neovascularization (CNV) and leads to exudative retinal detachment, subretinal hemorrhage, lipid exudation, and outer retinal degeneration [6-8]. Current proven treatments for CNV are generally associated with poor visual outcome, and not all AMD patients with CNV are eligible for treatment with these modalities because of the size of the neovascular complex or its lesion components (e.g., presence of mixed classic-occult neovascularization or large pigment epithelial detachment) [9-14]. As a result of these limitations, a number of different approaches to CNV management are being explored, including pharmacological therapy, gene therapy, macular translocation, and cell transplantation. At this time, whether any of these approaches will be both sight restoring and applicable to the majority of AMD patients with CNV is unclear.

\footnotetext{
Abbreviations: $\mathrm{AMD}=$ age-related macular degeneration, ANOVA $=$ analysis of variance, BCE-ECM = bovine corneal endothelial cell extracellular matrix, $\mathrm{CNV}=$ choroidal neovascularization, DMEM = Dulbecco's modified Eagle's medium, $\mathrm{ECM}=$ extracellular matrix, $\mathrm{ICL}=$ inner collagenous layer, PBS = phosphate buffered saline, RPE = retinal pigment epithelium.

${ }^{*}$ Address all correspondence to Marco A. Zarbin, MD, PhD; Institute of Ophthalmology and Visual Science, UMDNJ New Jersey Medical School, 90 Bergen St, PO Box 1709, Newark, NJ 07103; 973-972-2065; fax: 973-972-2068. Email: zarbin@umdnj.edu

DOI: 10.1682/JRRD.2005.06.0114
} 
$\mathrm{CNV}$ excision can be done with vitrectomy and specialized microsurgical instruments for subretinal surgery. CNV excision offers the possibility of removing large CNV while preserving the overlying retina, thus preventing/ reversing the photoreceptor damage and blindness associated with subretinal bleeding and scarring in AMD. However, visual recovery after CNV excision in AMD patients is usually poor because of removal of adjacent native retinal pigment epithelium (RPE) and damage to the subjacent Bruch's membrane (i.e., removal of the RPE basement membrane and, to varying degrees, portions of the inner collagenous layer [ICL] of the Bruch's membrane) [15-16] as well as incomplete RPE growth into the dissection bed with subsequent choriocapillaris and photoreceptor atrophy $[15,17]$. While these findings indicate that RPE transplantation might improve visual outcome after $\mathrm{CNV}$ excision in AMD patients, allogeneic RPE transplants in AMD patients that have undergone CNV excision have failed with poor visual outcome and, in patients who are not immune suppressed, subretinal fibrosis and chronic fluid leakage in the dissection bed [18-22]. Immune rejection and graft failure may underlie these results.

An alternative to RPE transplantation is to stimulate RPE regrowth from the edge of the dissection bed [23]. Using aged submacular human Bruch's membrane explants in organ culture, we reproduced the incomplete and aberrant RPE resurfacing seen in AMD patients following CNV excision [24]. These experiments demonstrated that resurfacing was significantly better when RPE basement membrane or the ICL immediately below the RPE basement membrane was present. Poor or no resurfacing was noted if the deeper ICL or the lamina elastica was exposed. Primary extracellular matrix (ECM) ligands in RPE basement membrane include collagen IV and laminin [25]. The ICL comprises predominantly fibronectin and collagen I. Fibronectin is present mostly in the superficial ICL and immediately beneath the RPE basement membrane [26]. The results of these wound-healing studies led us to pose the following two questions. First, is the poor wound healing by aged RPE because of the aging of RPE cells? Second, is the difference in RPE wound healing on different layers of Bruch's membrane caused by altered availability of different ECM ligands on aged submacular Bruch's membrane?

This study answers these questions by comparing migration and proliferation of aged RPE versus fetal RPE on bovine corneal endothelial ECM (BCE-ECM) and on individual ECM ligands (i.e., laminin, collagen IV, fibronectin, and collagen I). Previous studies indicate that aged human RPE can grow on BCE-ECM [27]. In addition, we compared the ability of aged adult and fetal cells to migrate on human versus nonhuman ligands.

\section{METHODS}

\section{Donor Eyes}

Aged human donor eyes were obtained through the National Disease Research Interchange (Philadelphia, Pennsylvania) and the North Carolina Eye Bank (Salem, North Carolina), a Vision Share member eye bank. The donor inclusion criteria were (1) no history of chemotherapy or radiation to the head, (2) not on a ventilator prior to death, (3) $5 \mathrm{~h}$ from death to enucleation with eyes preserved in a moist chamber and stored on ice immediately after removal, (4) $48 \mathrm{~h}$ from death to experimentation, and (5) intact RPE under the macula as visualized through a dissecting microscope. Fetal eyes were obtained from the Central Laboratory for Human Embryology (University of Washington, Seattle, Washington). This research followed the tenets of the Declaration of Helsinki and was approved by the institutional review board of the New Jersey Medical School.

\section{Isolation of Human RPE Microaggregates}

Eyes were immersed briefly in 10 percent povidoneiodine (Betadine ${ }^{\circledR}$ solution; Purdue Frederick Company, Norwalk, Connecticut) after remnants of conjunctiva, Tenon's capsule, extraocular muscles, and orbital fat were removed carefully under a dissecting microscope. Eyes were then rinsed in Dulbecco's modified Eagle's medium (DMEM) (Mediatech, Herndon, Virginia) twice for 5 min each. A circumferential incision was made posterior to the ora serrata through the sclera and underlying choroid so that by cutting the retina around the optic disc, the vitreous, neural retina, and anterior segment were removed without damaging the RPE surface. RPE-choroid layers were detached from the sclera and incubated in $0.4 \mathrm{mg} / \mathrm{mL}$ collagenase type IV for 30 to 45 min for adult RPE and $0.8 \mathrm{mg} / \mathrm{mL}$ collagenase type IV for 1 to $2 \mathrm{~h}$ for fetal RPE. The conditions for harvesting adult RPE were determined in a previously published study [27]. Optimal conditions for fetal RPE harvesting were not conducive to healthy adult RPE harvesting [27]. The harsher conditions (i.e., higher collagenase concentration, longer incubation time) 
do not appear to affect fetal RPE attachment or growth as evidenced by the results of this study and unpublished observations on establishment of fetal RPE cell lines used routinely by this laboratory. RPE sheets were dissected carefully from the choroid at the end of the incubation and gently trimmed to form microaggregates. RPE microaggregates were then plated on BCE-ECM [28] or ECM ligand-coated cultured dishes/wells. Cells were cultured in DMEM containing 15 percent fetal bovine serum, $2 \mathrm{mM}$ L-glutamine, $2.5 \mathrm{~g} / \mathrm{mL}$ amphotericin $\mathrm{B}, 0.05 \mathrm{mg} / \mathrm{mL}$ gentamicin, and $1 \mathrm{ng} / \mathrm{mL}$ basic fibroblastic growth factor at $37^{\circ} \mathrm{C}$ in 10 percent carbon dioxide. Culture medium was changed every other day.

\section{Monitoring Ongoing RPE Growth}

RPE growth was observed daily with an inverted phase microscope (Axiovert 135, Carl Zeiss, Oberkochen, Germany), and photographs were taken at Day 1 when the patches were fully attached and again at Day 10 before the patches were fixed for immunocytochemistry.

\section{Immunocytochemistry with Confocal Microscope}

We identified proliferating RPE cells by immunolabeling them with an antibody against Ki-67, a nuclear antigen present in the proliferating cells. At Day 10, RPE patches were fixed lightly in 4 percent formaldehyde for $1 \mathrm{~h}$ followed by extensive rinsing with phosphate buffered saline (PBS). Patches were then blocked with 2 percent normal goat serum, 0.5 percent bovine serum albumin, and 0.1 percent Triton X-100 for 45 min. Prediluted Ki-67 antibody (Zymed Laboratories, Inc, San Francisco, California) was then applied. Following incubation at $4{ }^{\circ} \mathrm{C}$ overnight and extensive rinses with PBS, patches were incubated in secondary antibody (Cy5, conjugated goat antimouse antibody [Jackson Immuno-Research Laboratories, Inc, West Grove, Pennsylvania]) in the dark at room temperature for $1.5 \mathrm{~h}$. Immunofluorescent labeling was observed with a confocal microscope (LSM 510 META, Carl Zeiss, Oberkochen, Germany; 633 nm [long pass $650 \mathrm{~nm}$ for Cy5] and $488 \mathrm{~nm}$ [long pass 505 for RPE autofluorescence]). To document RPE cell proliferation, we took photographs of Ki-67 labeling and RPE autofluorescence with a maximum laser pinhole. Fetal RPE were counterstained with crystal violet following fluorescence imaging. To image crystal violet staining, we obtained bright-field images and resized them to correspond to the confocal images.

\section{Experimental Design}

Five pairs of adult human donor eyes of age 62 to 80 (mean age \pm standard deviation $=72.0 \pm 7.3$ ) and three pairs of fetal donor eyes (101, 108, and 120 days of age) were used to study RPE migration and proliferation on BCE-ECM or human ECM ligand-coated 96-well culture dishes (i.e., laminin, fibronectin, collagens I and IV [CytoMatrix cell adhesion strips, Chemicon International, Temecula, California]). We used another three pairs of human donor eyes of ages 64, 70, and 71 to compare RPE growth on human fibronectin versus nonhuman ECM ligands: BCE-ECM, mouse laminin, mouse collagen IV, and rat collagen I were coated onto $35 \mathrm{~mm}$ culture dishes (BD Scientific, Franklin Lakes, New Jersey). In addition, we used one pair of fetal donor eyes (108 days) to study RPE outgrowth on $35 \mathrm{~mm}$ culture dishes coated with mouse laminin, rat collagen I, BCE-ECM, and human fibronectin. Human fibronectin was included in these studies for comparison with cell migration on a human ECM ligand for each group of donor cells. One to five RPE patches from a pair of donor eyes were studied for each ligand. For 96-well culture dishes, one patch was placed in each well; for $35 \mathrm{~mm}$ culture dishes, widely separated patches were placed on a single ligand-coated dish.

\section{Image Analysis}

Montages of phase or crystal violet staining and Ki-67labeling images at Day 10 were created from individual images with Adobe Photoshop 6.0 (Adobe Systems, Mountain View, California). Original edges of RPE patches were marked on phase or crystal violet images by overlaying Day 1 images onto Day 10 montages. To measure the amount of RPE outgrowth between samples and to normalize for the differences in size of the original patches, we expressed the migration "index" as the area of RPE outgrowth divided by the area of the original RPE patch. For adult RPE, before combining and averaging migration indices for all donors on a single ligand, we used single factor analysis of variance (ANOVA) to detect whether a significant difference occurred between donors. We used ANOVA and Tukey multiple comparison tests to compare migration indices between different ECM ligands. We were unable to accurately assess area covered by fetal RPE in 96-well culture dishes (human ECM ligands and BCE-ECM) since on some of the ligands studied (e.g., BCE-ECM), rapid outgrowth and/or asymmetrical attachment of the patches led to areas of outgrowth abutting the edge of the well by Day 10 . 
Therefore, assessment of fetal RPE outgrowth in 96-well dishes, estimated from overlays, was scored on a scale of 1 to 4 by assigning patches with no or minimal outgrowth a score of 1 and those with the most outgrowth a score of 4 . The location and amount of Ki-67 labeling was evaluated with the original edge of the RPE patch and the leading edge at Day 10 as points of reference.

\section{RESULTS}

\section{Migration and Proliferation of Aged Human RPE on Human ECM Ligands and BCE-ECM}

By Day 2, all patches seeded onto 96-well culture dishes coated with BCE-ECM and human ECM ligands were attached and some cells had spread out from the origi- nal RPE patches on all surfaces. At Day 10, the covered areas on all surfaces were significantly enlarged (Figure 1, Table 1). Although the underlying substrate appeared to affect outgrowth, robustness of outgrowth was also donor dependent. Most cells covering the surfaces appeared flattened and in contact with each other. Single migrating cells were also seen at the migration leading edge. The covered areas were not significantly different between all surfaces studied (ANOVA, $p>0.05$ ).

At Day 10, Ki-67-positive RPE cells were observed throughout the covered areas outside the original patch, with most of the positive cells seen in the zone between the original edge and the outgrowing leading edge (an area termed the transitional zone) (Figure 2). The numbers of proliferating RPE cells did not appear different between all surfaces studied. (a)

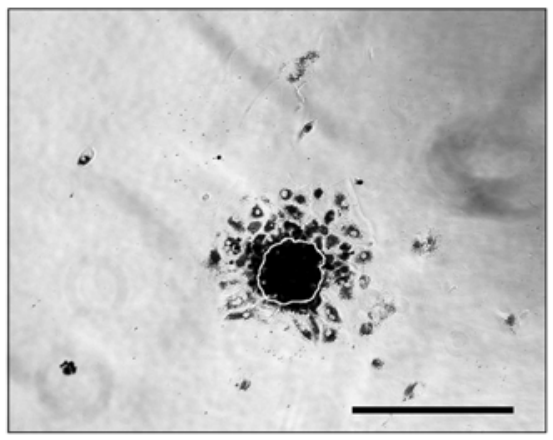

(d)

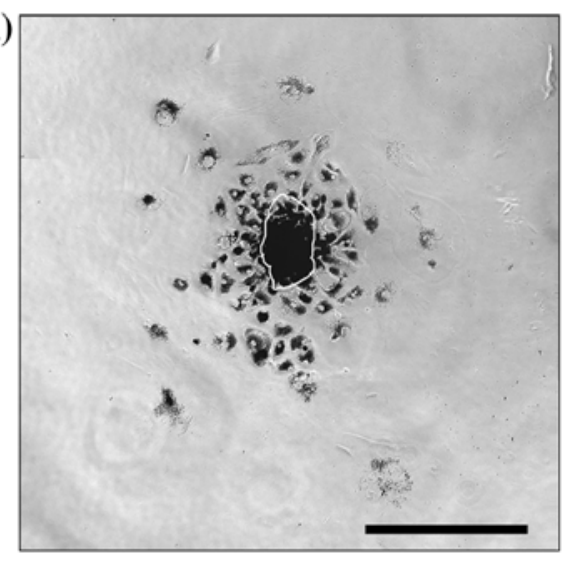

(b)

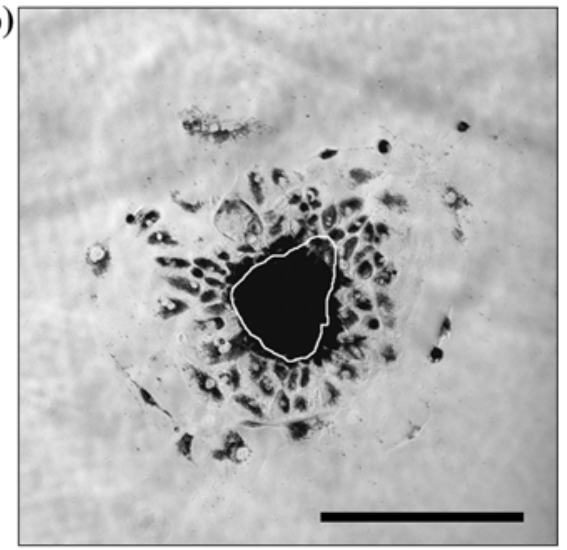

(e)

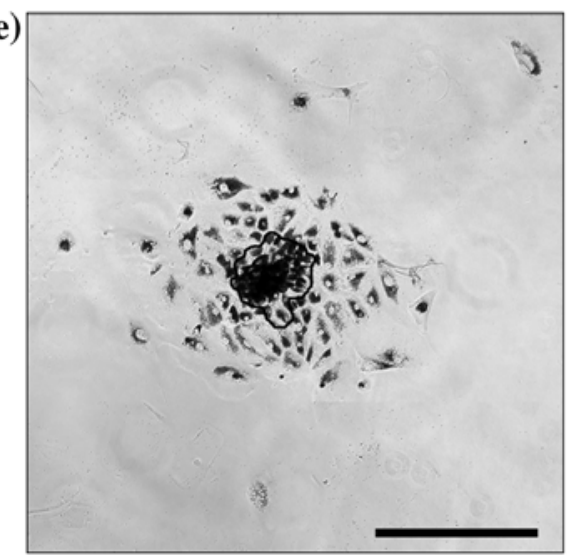

(c)

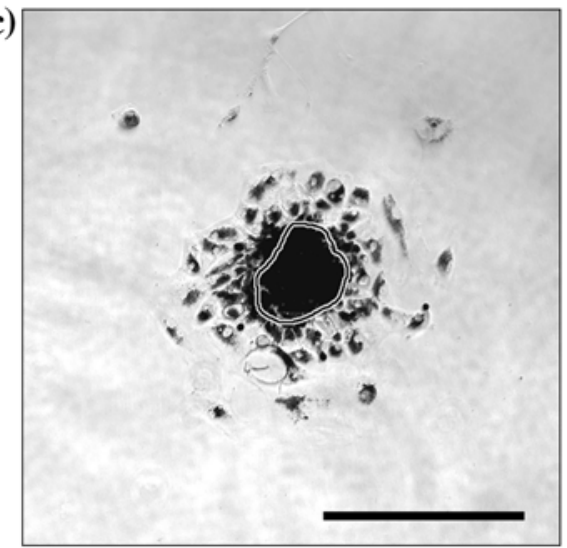

Figure 1.

Aged human retinal pigment epithelium (RPE) (donor age $=80 \mathrm{yr}$ ) migration and proliferation on human extracellular matrix (ECM) ligands Patches of RPE were seeded onto (a) human laminin, (b) human collagen IV, (c) human collagen I, and (d) human fibronectin. (e) Cells seeded onto bovine corneal endothelial cell ECM are included for comparison. (a-e) 10 days in culture. Outline = original patch edge. Magnification bar $=400 \mu \mathrm{m}$. 
Table 1.

Migration of aged human retinal pigment epithelium (RPE) onto human extracellular matrix (ECM) ligand-coated 96-well dishes (bovine corneal endothelial ECM [BCE-ECM] included for comparison) $\left(N=5^{*}\right)$.

\begin{tabular}{lc}
\hline Ligand & Migration Index $^{\dagger}$ \\
\hline Laminin & $8.86 \pm 3.05$ \\
Collagen IV & $10.74 \pm 7.00$ \\
Fibronectin & $10.71 \pm 7.26$ \\
Collagen I & $5.43 \pm 2.51$ \\
BCE-ECM & $12.86 \pm 5.70$
\end{tabular}

${ }^{*}$ Number of donor eye pairs. RPE from each donor pair combined prior to seeding; 1 to 5 patches from each donor pair studied per ECM ligand.

${ }^{\dagger}$ Total area covered at Day 10 divided by area of original patch. No significant difference is present between ligands (analysis of variance, $p>0.05$ ). Data presented as mean \pm standard of error of the mean.

\section{Migration and Proliferation of Aged Human RPE on BCE-ECM, Nonhuman ECM Ligands, and Human Fibronectin}

By Day 2, all RPE patches seeded onto $35 \mathrm{~mm}$ culture dishes coated with BCE-ECM, mouse collagen IV, rat collagen I, and human fibronectin were attached and some cells had spread out from the original patches. For RPE seeded onto mouse laminin-coated dishes, all patches were attached by Day 2 in two donors, whereas most patches were floating at Day 2 and became attached at Day 4 in one donor. At Day 10, the covered areas on BCE-ECM, mouse collagen IV, rat collagen I, and human fibronectin were significantly enlarged with most outgrowing cells appearing flattened and in contact with each other (Figure 3, Table 2). Single migrating cells were at the migration leading edge. Although the underlying substrate appeared to affect outgrowth, robustness of outgrowth was also donor dependent.

In most cases, the covered areas were not significantly different between the various nonhuman ECM ligands and the human fibronectin. However, the covered area on mouse laminin was significantly less than on other ECM ligands, with only a few cells migrating outside the original patches by Day 10 (Tukey multiple comparison tests, $q>0.05,10,5$ for $p=0.05$ ). Cells growing on mouse laminin were small and less flat than on other surfaces. Rounded cells were also seen on the mouse laminin. For all other nonhuman ECM ligands, Ki-67-positive RPE cells were observed throughout the covered areas outside the original patch at Day 10, with most positive cells in the transitional zone and at the outgrowing leading edge. This pattern of Ki-67 labeling was similar to that of cells migrating on human fibronectin. The numbers of proliferating RPE cells did not appear to be significantly different between the various ECM ligand coated surfaces studied. (a)

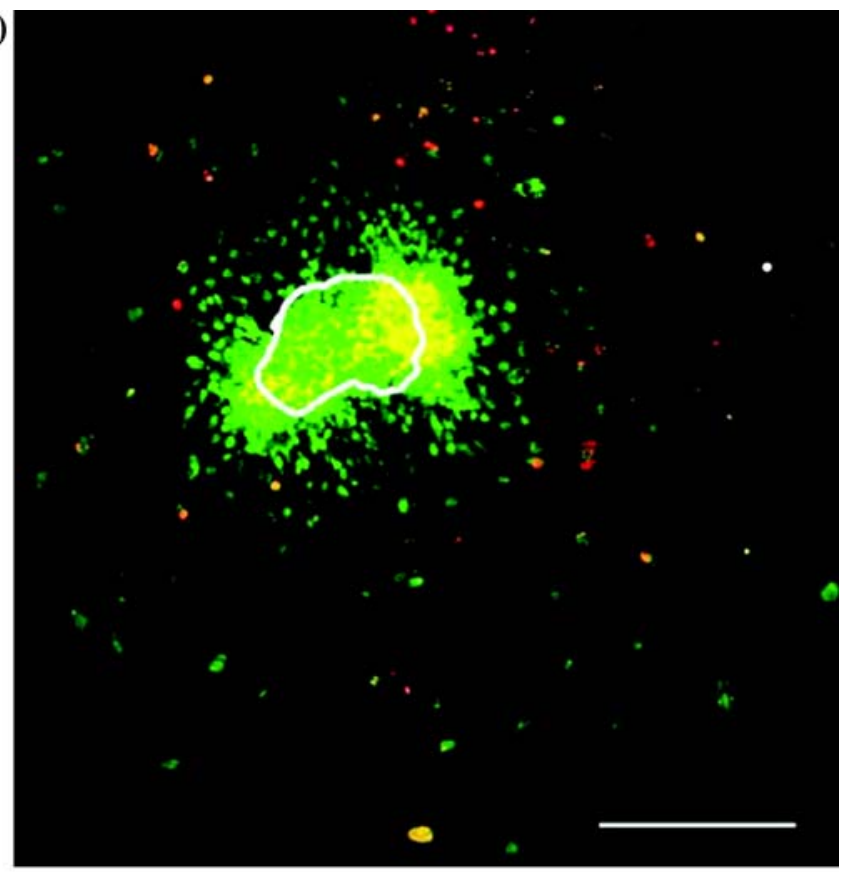

(b)

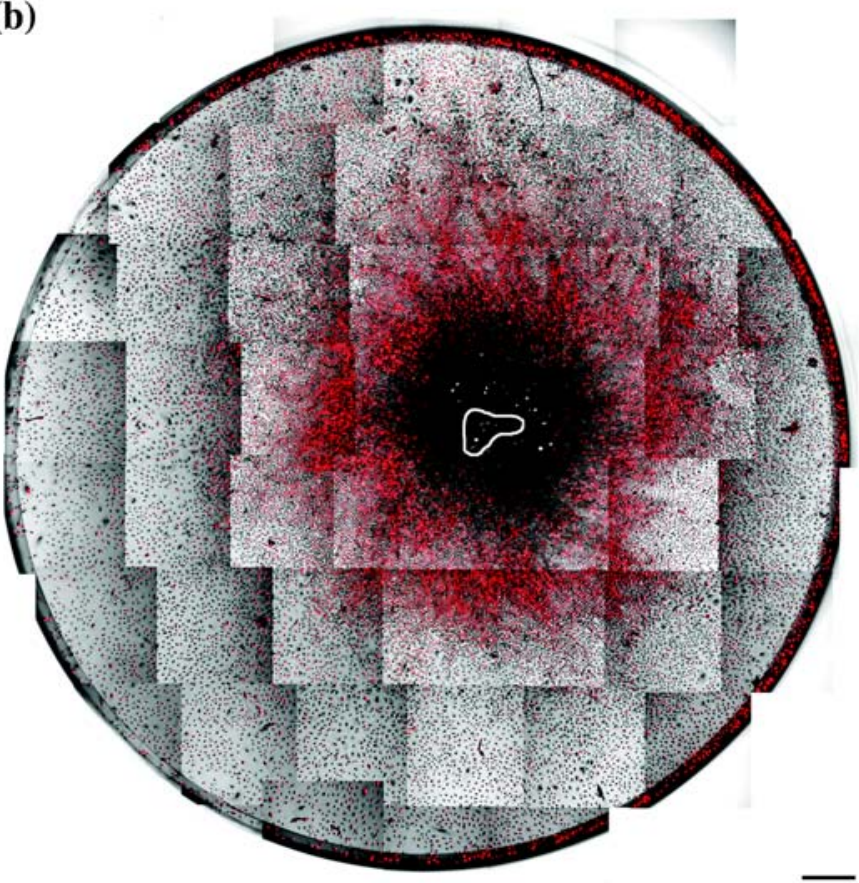

Figure 2.

Role of cell proliferation in resurfacing bovine corneal endothelial cell extracellular matrix Ki-67 staining. (a) Adult human retinal pigment epithelium (RPE) (donor age = $70 \mathrm{yr}$ ); Ki-67 (red), autofluorescence in adult RPE (green). (b) Fetal human RPE, crystal violet image overlaid with red Ki-67 label. Proliferation is much greater in fetal than adult specimens. Outline = original patch edge. Magnification bar $=400 \mu \mathrm{m}$. 
(a)

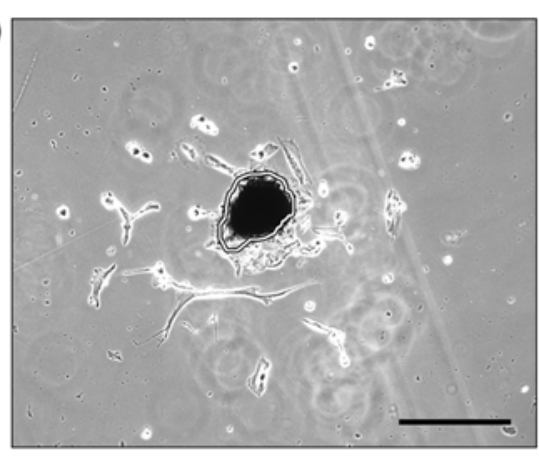

(d)

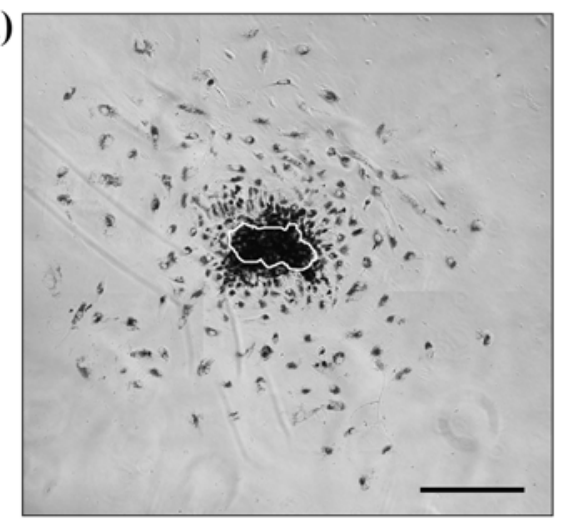

(b)

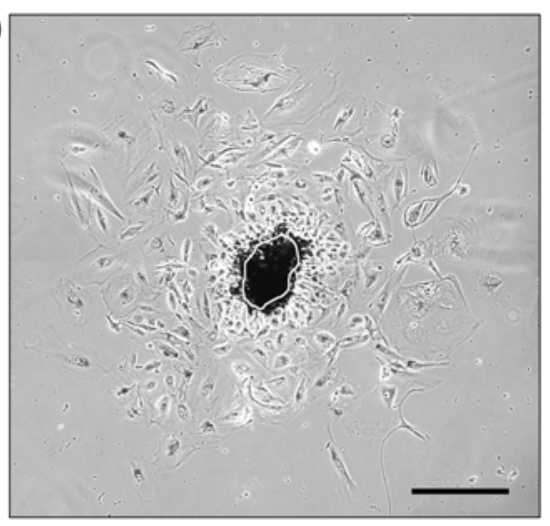

(e)

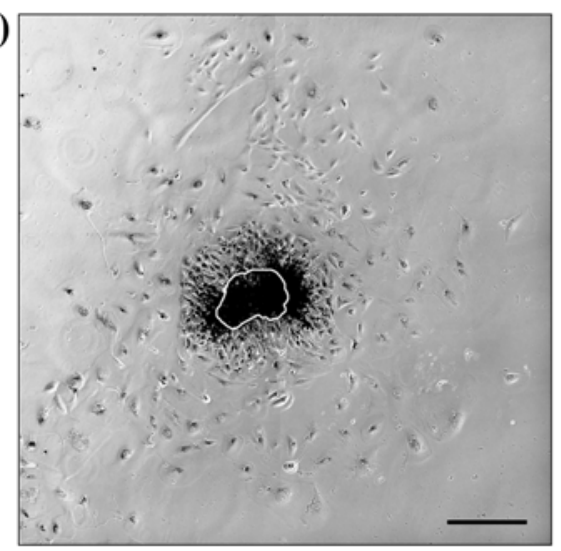

(c)

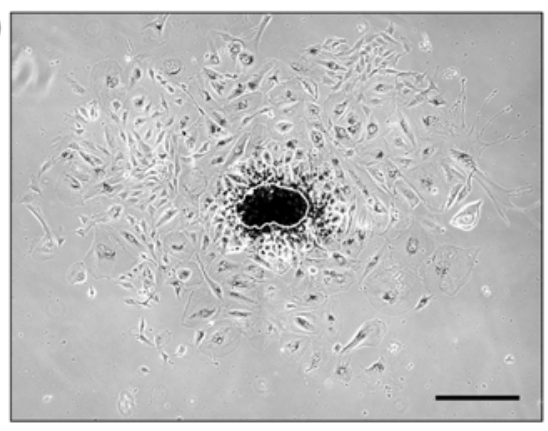

Figure 3.

Aged human retinal pigment epithelium (RPE) (donor age = $70 \mathrm{yr}$ ) migration and proliferation on rodent extracellular matrix (ECM) ligands. (a) Patches of human RPE seeded onto mouse laminin, (b) mouse collagen IV, and (c) rat collagen I. (d) Cells seeded onto human fibronectin and (e) bovine corneal endothelial ECM (BCE-ECM) are included for comparison. (a-e) 10 days in culture. Note that migration on BCE-ECM and fibronectin is more vigorous than that observed in Figure 1, probably because of donor variability. Outline = original patch edge. Magnification bar $=400 \mu \mathrm{m}$.

Table 2.

Migration of aged human retinal pigment epithelium (RPE) onto nonhuman extracellular matrix (ECM) ligand-coated $35 \mathrm{~mm}$ dishes (human fibronectin included for comparison) $\left(N=3^{*}\right)$.

\begin{tabular}{lc}
\hline \multicolumn{1}{c}{ Ligand } & Migration Index $^{\dagger}$ \\
\hline Laminin (mouse) & $6.56 \pm 3.25$ \\
Collagen IV (mouse) & $32.95 \pm 4.33$ \\
Fibronectin (human) & $36.39 \pm 3.92$ \\
Collagen I (rat) & $33.95 \pm 5.20$ \\
BCE-ECM & $29.46 \pm 9.66$
\end{tabular}

${ }^{*}$ Number of donor eye pairs. RPE from each donor pair combined prior to seeding; 1 to 5 patches from each donor pair studied per ECM ligand.

${ }^{\dagger}$ Total area covered at Day 10 divided by area of original patch. Data presented as mean \pm standard error of the mean. Migration on laminin is significantly different from other ligands studied. Tukey multiple comparison tests show calculated $q>0.05,10,5$ for $p=0.05$.

BCE-ECM = bovine corneal endothelial extracellular matrix.

\section{Migration and Proliferation of Fetal Human RPE on BCE-ECM and Human ECM Ligands}

By Day 2, all patches seeded onto 96-well culture dishes coated with BCE-ECM, human collagen IV, human collagen I, human laminin, and human fibronectin were attached and some cells had spread out from the original patches. At Day 10, the covered areas on BCE-ECM, human collagen IV, human collagen I, and human fibronectin were enlarged significantly (Table 3). Most outgrowing cells appeared flattened and in contact with each other. Single migrating cells were seen at the migration leading edge. In the BCE-ECM-coated plates particularly, the amount of coverage approached 100 percent. The covered area on human laminin was significantly less than on other ECM ligands (Table 3, Figure 4). At Day 10, Ki67-positive RPE cells were seen throughout the covered 
areas in all surfaces studied. The frequency of proliferating cells was significantly greater than that of aged adult RPE on the same ECM ligands (Figure 2).

Table 3.

Migration of human fetal retinal pigment epithelium (RPE) onto extracellular matrix (ECM) ligand-coated 96-well dishes (bovine corneal endothelial ECM [BCE-ECM] included for comparison).

\begin{tabular}{lcc}
\hline \multicolumn{1}{c}{ Ligand } & $\boldsymbol{N}^{*}$ & Migration ${ }^{\dagger}$ \\
\hline Laminin & 2 & 2 \\
Collagen IV & 2 & 3 \\
Fibronectin & 3 & 3 \\
Collagen I & 2 & 3 \\
BCE-ECM & 3 & 4
\end{tabular}

*Number of donor eye pairs. RPE from each donor pair combined prior to seeding; 1 to 5 patches from each donor pair studied per ECM ligand.

${ }^{\dagger}$ Assessment of migration and area covered is qualitative and is expressed on scale of 1 to 4 ( 1 = no or little growth; 4 = maximum growth $)$.

\section{Migration and Proliferation of Fetal RPE on Nonhuman ECM Ligands and Human Fibronectin}

Compared with aged adult RPE at Day 10, fetal RPE patches showed significantly greater coverage on all ECM ligands except mouse laminin-coated dishes, on which minimal coverage was observed (Table 4, Figure 4). For fetal RPE, the covered area on BCE-ECM appeared to be the greatest and no obvious difference was observed between the area covered on fibronectin versus collagen I.

At Day 10, Ki-67-positive RPE cells were seen throughout the covered area in all surfaces studied except for mouse laminin. The frequency of proliferating cells was significantly greater than that of aged adult RPE on the same ECM ligands. (a)

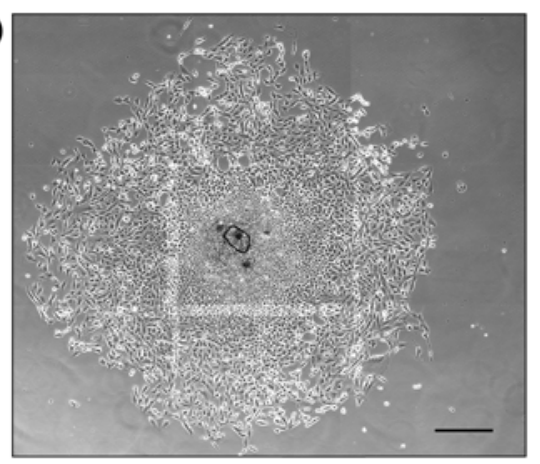

(d)

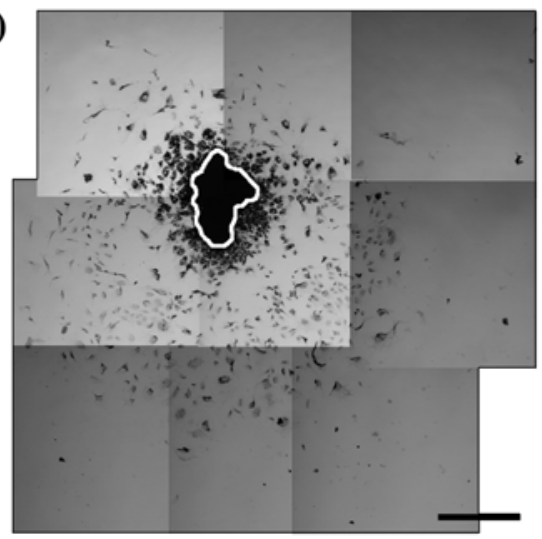

(b)

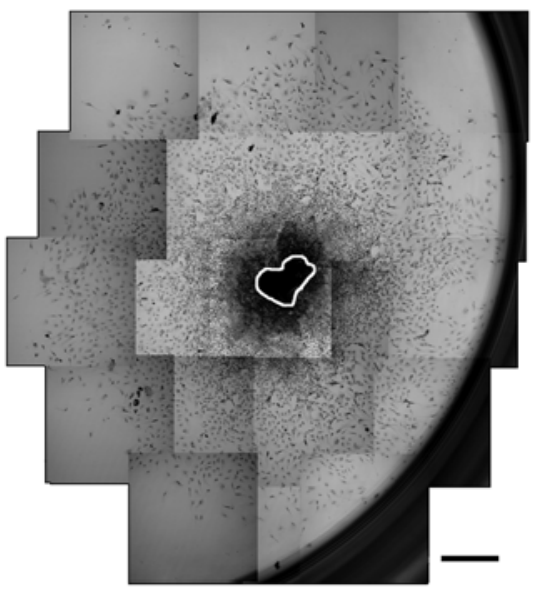

(e)

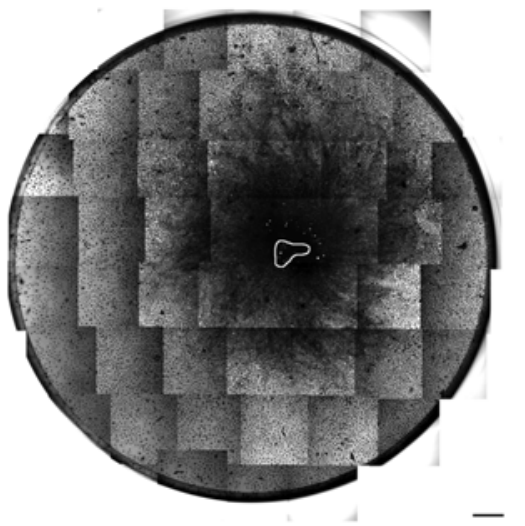

(c)

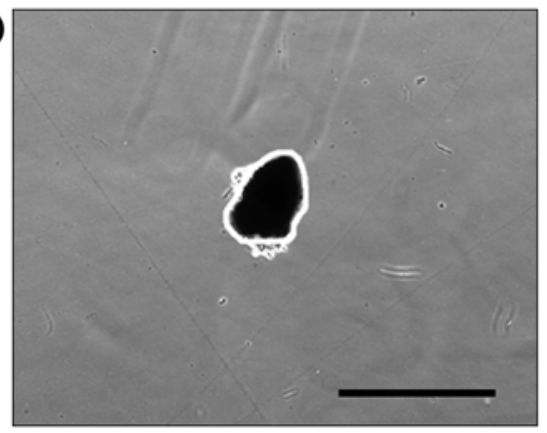

Figure 4.

Fetal human retinal pigment epithelium (RPE) migration and proliferation on rodent versus human extracellular matrix (ECM) ligands. Patches of fetal RPE were seeded onto (a) rat and (b) human collagen I and (c) mouse and (d) human laminin after 10 days in culture. (e) Cells seeded onto bovine corneal endothelial cell ECM are included for comparison. Outline = original patch edge. (b-e) Crystal violet counterstain. Magnification bar $=400 \mu \mathrm{m}$. 
Table 4.

Migration of human fetal retinal pigment epithelium (RPE) onto extracellular matrix (ECM) ligand-coated $35 \mathrm{~mm}$ dishes (human fibronectin included for comparison) $\left(N=1^{*}\right)$.

\begin{tabular}{lc}
\hline \multicolumn{1}{c}{ Ligand } & Migration Index ${ }^{\dagger}$ \\
\hline Laminin (mouse) & 0.51 \\
Fibronectin (human) & 365.5 \\
Collagen I (rat) & 313.6 \\
BCE-ECM & 809.4
\end{tabular}

${ }^{*}$ Number of donor eye pairs; 1 to 2 patches from each donor pair studied per ECM ligand.

${ }^{\dagger}$ Total area covered at Day 10 divided by area of original patch. BCE-ECM = bovine corneal endothelial extracellular matrix.

\section{DISCUSSION}

The results of these experiments indicate that agerelated changes in RPE cells may compromise RPE wound healing, but a high density of single ECM ligands can support aged RPE migration. The source of collagen (rat or mouse) did not appear to adversely affect outgrowth of RPE. The results observed with migration on laminin, however, indicate that the source of the ECM ligand can play an important role in the migratory ability of the cells. In view of the limited native RPE resurfacing observed in areas of localized RPE debridement using organ cultures of aged submacular human Bruch's membrane [24], ECM ligand bioavailability is likely compromised in the submacular area of aged human eyes. Development of Bruch's membrane treatments that foster RPE migration into the dissection bed might be accomplished with a high density of single or complex ligand surfaces. In this regard, we note that RPE resurfacing was consistently best on BCE-ECM. The composition of BCE-ECM is documented [29-34]. We suspect that BCE-ECM had the greatest effect on RPE resurfacing because (1) it contains a high density of relevant ECM ligands and (2) the ECM ligands are organized in a suitable three-dimensional array.

\section{CONCLUSIONS}

The goal of our research is to develop sight-restoring, cell-based therapy for people with AMD. Combining RPE transplantation with CNV excision may provide a sightrestoring therapy for selected AMD patients. In view of the challenges of RPE transplantation (e.g., management of transplant rejection), stimulation of RPE resurfacing seems attractive, since it essentially uses the patient's native RPE cells to support cell-based therapy. The availability of techniques to manufacture surfaces that are biocompatible and that exhibit ECM ligands supporting cell attachment, proliferation, and survival renders biochemical reconstruction of Bruch's membrane a viable approach for managing RPE cell loss after surgical excision of CNVs as well as in cases of geographic atrophy [35-36].

\section{ACKNOWLEDGMENTS}

This material was based on work supported by the Foundation Fighting Blindness, Owings Mills, Maryland; an unrestricted grant from Research to Prevent Blindness, New York, New York; The Foundation of the University of Medicine and Dentistry of New Jersey, Newark, New Jersey; Lions Eye Research Foundation of New Jersey, Newark, New Jersey; The Eye Institute of New Jersey, Newark, New Jersey; The Macula Society, Cleveland, Ohio; The William G. \& Helen C. Hoffman Foundation, Summit, New Jersey, the National Institutes of Health (grant NEI 09750); The Janice Mitchell Vassar and Ashby John Mitchell Fellowship; and a gift from Mrs. Georgaynne Holst-Knudsen.

Dr. Zarbin is a paid consultant for Novartis AG; Genetech, Inc; Wyeth; and Celgene, Corp. Dr. Zarbin has received funding support from Johnson \& Johnson for an unrelated study.

The authors have declared that no competing interests exist.

\section{REFERENCES}

1. Klein R, Klein BE, Linton KL. Prevalence of age-related maculopathy. The Beaver Dam Eye Study. Ophthalmology. 1992;99(6):933-43. [PMID: 1630784]

2. Sommer A, Tielsch JM, Katz J, Quigley HA, Gottsch JD, Javitt JC, Martone JF, Royall RM, Witt KA, Ezrine S. Racial differences in the cause-specific prevalence of blindness in east Baltimore. N Engl J Med. 1991;325(20): 1412-17. [PMID: 1922252]

3. Klein R, Wang Q, Klein BE, Moss SE, Meuer SM. The relationship of age-related maculopathy, cataract, and glaucoma to visual acuity. Invest Ophthalmol Vis Sci. 1995; 36(1):182-91. [PMID: 7822146] 
4. Attebo K, Mitchell P, Smith W. Visual acuity and the causes of visual loss in Australia. The Blue Mountains Eye Study. Ophthalmology. 1996;103(3):357-64. [PMID: 8600410]

5. Rosenberg T, Klie F. Current trends in newly registered blindness in Denmark. Acta Ophthalmol Scand. 1996;74(4): 395-98. [PMID: 88883558]

6. Vingerling JR, Dielemans I, Hofman A, Grobbee DE, Hijmering M, Kramer CF, De Jong PT. The prevalence of age-related maculopathy in the Rotterdam Study. Ophthalmology. 1995;102(2):205-10. [PMID: 7862408]

7. Mitchell P, Smith W, Attebo K, Wang JJ. Prevalence of age-related maculopathy in Australia. The Blue Mountains Eye Study. Ophthalmology. 1995;102(10):1450-60. [PMID: 9097791]

8. Klein R, Klein BE, Jensen SC, Meuer SM. The five-year incidence and progression of age-related maculopathy: The Beaver Dam Eye Study. Ophthalmology. 1997;104(1):7-21. [PMID: 9022098]

9. Freund KB, Yannuzzi LA, Sorenson JA. Age-related macular degeneration and choroidal neovascularization. Am J Ophthalmol. 1993;115(6):786-91. [PMID: 7685148]

10. Bressler NM, Treatment of age-related macular degeneration with photodynamic therapy (TAP) study group. Photodynamic therapy of subfoveal choroidal neovascularization in age-related macular degeneration with verteporfin: Two-year results of 2 randomized clinical trials-TAP report 2. Arch Ophthalmol. 2001;119(2):198-207. [PMID: 11176980]

11. Olsen TW, Feng X, Kasper T, Rath PP, Steuer ER. Exudative age-related macular degeneration: Fluorescein angiographic subtype prevalence. Invest Ophthalmol Vis Sci. 2001;42(4): S311.

12. Verteporfin in Photodynamic Therapy Study Group. Verteporfin therapy of subfoveal choroidal neovascularization in age-related macular degeneration: Two-year results of a randomized clinical trial including lesions with occult with no classic choroidal neovascularization-Verteporfin in photodynamic therapy report 2. Am J Ophthalmol. 2001; 131(5):541-60. [PMID: 11336929]

13. Blinder KJ, Bradley S, Bressler NM, Bressler SB, Donati G, Hao Y, Ma C, Menchini U, Miller J, Potter MJ, Pournaras C, Reaves A, Rosenfeld PJ, Strong HA, Stur M, Su XY, Virgili G. Effect of lesion size, visual acuity, and lesion composition on visual acuity change with and without verteporfin therapy for choroidal neovascularization secondary to age-related macular degeneration: TAP and VIP report no. 1. Am J Ophthalmol. 2003;136(3):407-18. [PMID: 12967792]

14. Gragoudas ES, Adamis AP, Cunningham ET Jr, Feinsod M, Guyer DR. Pegaptanib for neovascular age-related macular degeneration. N Engl J Med. 2004;351(27):2805-16. [PMID: 15625332]

15. Nasir MA, Sugino I, Zarbin MA. Decreased choriocapillaris perfusion following surgical excision of choroidal neovascular membranes in age-related macular degeneration. Br J Ophthalmol. 1997;81(6):481-89. [PMID: 9274413]

16. Grossniklaus HE, Hutchinson AK, Capone A Jr, Woolfson J, Lambert HM. Clinicopathologic features of surgically excised choroidal neovascular membranes. Ophthalmology. 1994;101(6):1099-1111. [PMID: 7516516]

17. Castellarin AA, Nasir MA, Sugino IK, Zarbin MA. Progressive presumed choriocapillaris atrophy after surgery for age-related macular degeneration. Retina. 1998;18(2): 143-49. [PMID: 9564695]

18. Algvere PV, Berglin L, Gouras P, Sheng Y, Kopp ED. Transplantation of RPE in age-related macular degeneration: Observations in disciform lesions and dry RPE atrophy. Graefes Arch Clin Exp Ophthalmol. 1997;235(3): 149-58. [PMID: 9085110$]$

19. Del Priore L, Kaplan HJ, Tezel TH, Berger AS. Retinal pigment epithelium transplantation for subfoveal neovascularization in exudative age-related macular degeneration: A clinical trial. Boca Roton (FL): The Macula Society; 1998.

20. Gouras P, Algvere V. Retinal cell transplantation in the macula: New techniques. Vision Res. 1996;36(24):4121-25. [PMID: 9068863]

21. Algvere PV, Berglin L, Gouras P, Sheng Y. Transplantation of fetal retinal pigment epithelium in age-related macular degeneration with subfoveal neovascularization. Graefes Arch Clin Exp Ophthalmol. 1994;232(12):707-16. [PMID: 7534250]

22. Algvere PV, Gouras P, Dafgard Kopp E. Long-term outcome of RPE allografts in non-immunosuppressed patients with AMD. Eur J Ophthalmol. 1999;9(3):217-30.

[PMID: 10544978]

23. Sugino IK, Wang H, Zarbin MA. Age-related macular degeneration and retinal pigment epithelium wound healing. Mol Neurobiol. 2003;28(2):177-94. [PMID: 14576455$]$

24. Wang H, Ninomiya Y, Sugino IK, Zarbin MA. Retinal pigment epithelium wound healing on human Bruch's membrane explants. Invest Ophthalmol Vis Sci. 2003;44(5): 2199-2210. [PMID: 12714662]

25. Marshall GE, Konstas AG, Reid GG, Edwards JG, Lee WR. Type IV collagen and laminin in Bruch's membrane and basal linear deposit in the human macula. Br J Ophthalmol. 1992;76(10):607-14. [PMID: 1420043]

26. Das A, Frank RN, Zhang NL, Turczyn TJ. Ultrastructural localization of extracellular matrix components in human retinal vessels and Bruch's membrane. Arch Ophthalmol. 1990;108(3):421-29. [PMID: 2310346]

27. Ishida M, Lui GM, Yamani A, Sugino IK, Zarbin MA. Culture of human retinal pigment epithelial cells from peripheral scleral flap biopsies. Curr Eye Res. 1998;17(4):392-402. [PMID: 9561831] 
JRRD, Volume 43, Number 6, 2006

28. Song MK, Lui GM. Propagation of fetal human RPE cells: Preservation of original culture morphology after serial passage. J Cell Physiol. 1990;143(1):196-203. [PMID: 3218907]

29. Tseng SC, Savion N, Gospodarowicz D, Stern R. Characterization of collagens synthesized by cultured bovine corneal endothelial cells. J Biol Chem. 1981;256(7):3361-65. [PMID: 7204405]

30. Gospodarowicz D, Gonzalez R, Fujii DK. Are factors originating from serum, plasma, or cultured cells involved in the growth-promoting effect of the extracellular matrix produced by cultured bovine corneal endothelial cells? J Cell Physiol. 1983;114(2):191-202. [PMID: 6218176]

31. Robinson J, Gospodarowicz D. Glycosaminoglycans synthesized by cultured bovine corneal endothelial cells. J Cell Physiol. 1983;117(3):368-76. [PMID: 6418749]

32. Nevo Z, Gonzalez R, Gospodarowicz D. Extracellular matrix (ECM) proteoglycans produced by cultured bovine corneal endothelial cells. Connect Tissue Res. 1984;13(1): 45-57. [PMID: 6242396]
33. Sawada H, Furthmayr H, Konomi H, Nagai Y. Immunoelectronmicroscopic localization of extracellular matrix components produced by bovine corneal endothelial cells in vitro. Exp Cell Res. 1987;171(1):94-109. [PMID: 3305047]

34. Kay EP, Oh S. Modulation of type III collagen synthesis in bovine corneal endothelial cells. Invest Ophthalmol Vis Sci. 1988;29(2):200-207. [PMID: 3338880]

35. Richman GP, Tirrell DA, Asthagiri AR. Quantitatively distinct requirements for signaling-competent cell spreading on engineered versus natural adhesion ligands. J Control Release. 2005;101(1-3):3-12. [PMID: 15588889]

36. Langer R, Tirrell DA. Designing materials for biology and medicine. Nature. 2004;428(6982):487-92.

[PMID: 15057821]

Submitted for publication June 29, 2005. Accepted in revised form November 18, 2005. 